\title{
Ethnic differences in hepatic and systemic insulin sensitivity and their associated determinants in obese black and white South African women
}

\author{
Julia H. Goedecke ${ }^{1,2}$ - Dheshnie Keswell ${ }^{2}$ - Carsten Weinreich ${ }^{3}$ - Jia Fan ${ }^{4}$. \\ Jon Hauksson ${ }^{5}$ - Hendriena Victor ${ }^{2}$. Kristina Utzschneider ${ }^{6}$ - Naomi S. Levitt ${ }^{3}$. \\ Estelle V. Lambert ${ }^{2} \cdot$ Steven E. Kahn $^{6} \cdot$ Tommy Olsson $^{7,8}$
}

Received: 2 March 2015 / Accepted: 13 July 2015 /Published online: 1 August 2015

(C) Springer-Verlag Berlin Heidelberg 2015

\begin{abstract}
Aims/hypothesis There is evidence to suggest that ectopic fat deposition in liver and skeletal muscle may differ between black and white women resulting in organ-specific differences in insulin sensitivity. Accordingly, the aim of the study was to examine ethnic differences in hepatic and peripheral insulin sensitivity, and the association with hepatic and skeletal muscle lipid content, and skeletal muscle gene expression.

Methods In a cross-sectional study including 30 obese premenopausal black and white women, body composition (dual energy x-ray absorptiometry), liver fat and skeletal muscle (soleus and tibialis anterior) fat accumulation (proton-magnetic resonance spectroscopy), skeletal muscle gene expression, insulin sensitivity (two-step isotope labelled, hyperinsulinaemic-euglycaemic clamp with $10 \mathrm{mU} \mathrm{m}^{-2} \mathrm{~min}^{-1}$ and $40 \mathrm{mU} \mathrm{m}^{-2} \mathrm{~min}^{-1}$ insulin infusions), and serum adipokines were measured.

Results We found that, although whole-body insulin sensitivity was not different, obese white women presented
\end{abstract}

Electronic supplementary material The online version of this article (doi:10.1007/s00125-015-3720-7) contains peer-reviewed but unedited supplementary material, which is available to authorised users.

Julia H. Goedecke

julia.goedecke@mrc.ac.za

1 Non-Communicable Disease Research Unit, South African Medical Research Council, PO Box 19070, Tygerberg 7505, South Africa

2 Division of Exercise Science and Sports Medicine, Department of Human Biology, University of Cape Town, Cape Town, South Africa

3 Division of Diabetes and Endocrinology, Department of Medicine, University of Cape Town, Cape Town, South Africa

4 MRC/UCT Medical Imaging Research Unit, Department of Human Biology, University of Cape Town, Cape Town, South Africa with lower hepatic insulin sensitivity than black women (\% suppression of endogenous glucose production [\% supp EGP], median [interquartile range (IQR)]: 17 [5-51] vs $56[29-100] \%, p=0.002)$. While liver fat tended to be lower $(p=0.065)$ and skeletal muscle fat deposition tended to be higher $(p=0.074)$ in black compared with white women, associations with insulin sensitivity were only observed in black women (\% supp EGP vs liver fat: $r=-0.57, p<0.05$ and $\%$ supp EGP vs soleus fat: $r=-0.56, p<0.05$ ).

Conclusions/interpretation These findings may suggest that black women are more sensitive to the effects of ectopic lipid deposition than white women.

Keywords Black African · Ectopic fat · Ethnicity · Euglycaemic-hyperinsulinaemic clamp $\cdot$ Hepatic insulin sensitivity $\cdot$ Liver fat $\cdot$ Peripheral insulin sensitivity $\cdot$ Skeletal muscle lipid

5 Center for Medical Technology and Radiation Physics, Umeå University Hospital, Umeå, Sweden

6 Division of Metabolism, Endocrinology and Nutrition, Department of Medicine, VA Puget Sound Health Care System and University of Washington, Seattle, WA, USA

7 Department of Public Health and Clinical Medicine, Umeå University, Umeå, Sweden

8 Stellenbosch Institute for Advanced Study (STIAS), Wallenberg Research Centre, Stellenbosch University, Stellenbosch, South Africa 


$\begin{array}{ll}\begin{array}{ll}\text { Abbreviations } \\ \text { \% supp EGP }\end{array} & \begin{array}{l}\text { \% Suppression of endogenous glucose } \\ \text { production }\end{array} \\ \text { DXA } & \begin{array}{l}\text { Dual energy x-ray absorptiometry } \\ \text { Endogenous glucose production }\end{array} \\ \text { EGP } & \text { Extra-myocellular lipid } \\ \text { EMCL } & \text { Fat-free mass } \\ \text { FFM } & \text { Fat mass index } \\ \text { FMI } & \text { High sensitivity C-reactive protein } \\ \text { hs-CRP } & \text { Impaired fasting glucose } \\ \text { IFG } & \text { Impaired glucose tolerance } \\ \text { IGT } & \text { Intra-myocellular lipid } \\ \text { IMCL } & \text { Glucose infusion adjusting for circulating } \\ \text { M/I } & \text { insulin concentrations } \\ & \text { He-magnetic resonance spectroscopy } \\ \text { MRS } & \text { Rate of disposal } \\ \text { Rd } & \text { Respiratory exchange ratio } \\ \text { RER } & \text { Subcutaneous adipose tissue } \\ \text { SAT } & \text { Stearoyl-CoA desaturase 1 } \\ \text { SCD1 } & \text { Insulin sensitivity } \\ \text { S } & \text { Tibialis anterior } \\ \text { TA } & \text { Vesicle associated membrane protein } \\ \text { VAMP } & \text { Visceral adipose tissue } \\ \text { VAT } & \end{array}$

\section{Introduction}

Type 2 diabetes and insulin resistance are more prevalent in populations of African origin than white populations $[1,2]$, but the main site of insulin resistance in obese black women is not known. Ectopic fat deposition in liver and skeletal muscle may differ by ethnicity [3,4], resulting in organ-specific differences in insulin resistance. Whether this is related to tissue-specific alterations in insulin signalling among obese black women has, to our knowledge, not been studied.

Accordingly, in a sample of obese premenopausal black and white women, we sought to: (1) examine ethnic differences in hepatic and peripheral insulin sensitivity $\left(\mathrm{S}_{\mathrm{I}}\right) ;(2)$ measure differences in hepatic and skeletal muscle lipid content and their association with $\mathrm{S}_{\mathrm{I}}$; and (3) measure the expression of genes involved in insulin signalling, fat oxidation and inflammation in skeletal muscle, and their ethnicspecific associations with $\mathrm{S}_{\mathrm{I}}$.

\section{Methods}

Participant selection This cross-sectional study included 30 obese premenopausal black and white women, matched for age (30-45 years) and BMI $\left(\geq 30 \mathrm{~kg} / \mathrm{m}^{2}\right)$, with no known diseases, not pregnant or lactating, and who consumed $<20 \mathrm{~g}$ alcohol/day. The study was undertaken in accordance with the guidelines of The Declaration of Helsinki and approved by the University of Cape Town Faculty of Health Sciences Human Research Ethics Committee. Participants gave written informed consent prior to participation.

Testing procedures A questionnaire was administered to measure family history of type 2 diabetes, smoking, alcohol and dietary intake (food frequency) [5]. Physical activity was measured using actigraphy (ActiGraph LLC, Pensacola, FL, USA). Fat mass, fat-free mass (FFM), abdominal visceral adipose tissue (VAT) and subcutaneous adipose tissue (SAT) areas were measured by dual energy x-ray absorptiometry (DXA, Discovery-W, software 12.7.3.7; Hologic, Bedford, MA, USA).

Fasting blood samples were drawn for metabolites, insulin and adipocytokines before a standard $75 \mathrm{~g}$ OGTT. On another day, a two-step euglycaemic $( \pm 5 \mathrm{mmol} / \mathrm{l})$, hyperinsulinaemic clamp, with $6,6-\left[{ }^{2} \mathrm{H}_{2}\right]$ glucose isotope label was performed, with a $3 \mathrm{~h}$ low-dose insulin infusion $\left(10 \mathrm{mU} \mathrm{m}^{-2} \mathrm{~min}^{-1}\right)$, followed by a $2 \mathrm{~h}$ higher dose insulin infusion $\left(40 \mathrm{mU} \mathrm{m}^{-2} \mathrm{~min}^{-1}\right)$, with samples drawn and respiratory exchange ratio (RER) measured (Quark RMR, Cosmed, Rome, Italy) in the last $30 \mathrm{~min}$ of each period. Serum metabolites, insulin and adipocytokines were measured using standard techniques (Electronic Supplementary Material [ESM] Methods) and 6,6- $\left[{ }^{2} \mathrm{H}_{2}\right]$ glucose was measured using Agilent 6890 gas chromatograph and analysed using ChemStation software (Agilent Technologies, Palo Alto, CA, USA).

Hepatic, and intra- (IMCL) and extra-myocellular lipid (EMCL), and total lipid content of the soleus and tibialis anterior (TA) muscles of the calf were measured by ${ }^{1} \mathrm{H}$-magnetic resonance spectroscopy (MRS) and MRI, respectively, using a 3 Tesla scanner (GE Healthcare, Global Diagnostic Imaging, Pewaukee, WI, USA).

A biopsy was taken from the vastus lateralis muscle from which RNA was extracted and the expression of genes (ESM Table 1) was measured using the Applied Biosystems 7900HT Fast Real-time PCR system using standard cycling conditions (Applied Biosystems, Foster City, CA, USA) and expressed relative to $\beta 2$ microglobulin.

Statistics Differences in participant characteristics were compared using $\chi^{2}$ analysis, one-way analysis of variance and/or covariance, adjusting for fat mass index (FMI), which takes into account differences in height and fat mass between groups. Bivariate associations were explored using Pearson's correlation coefficients, which informed multiple regression analyses that included an interaction term (ethnicity $\times$ independent variable). Data were analysed using STATA version 11.1 (StataCorp, College Station, TX, USA). 


\section{Results}

Participant characteristics The obese white and black women were of similar age, BMI, FFM and VAT, but black women were shorter and had a greater \% body fat and FMI (Table 1). The women performed similar daily physical activity and consumed similar amounts of dietary fat. More white than black women consumed alcohol and had a family history of diabetes (26.7 vs $6.7 \%, p=0.087$ ). Serum adiponectin was higher in white than black women, but high sensitivity C-reactive protein (hs-CRP) and other circulating inflammatory markers (data not shown) were not different.

Liver fat tended to be higher in white than black women. Calf TA and soleus IMCL content were similar, but total soleus fat content was higher in black than white women. Skeletal muscle expression of genes involved in insulin signalling, glucose transport and fat oxidation did not differ between black and white women (ESM Table 1), nor did they correlate with any measure of skeletal muscle fat content.

Fasting glucose, insulin and NEFA concentrations did not differ by ethnicity. More white than black women had impaired fasting glucose (IFG; 26.7 vs $6.7 p=0.142$ ) and impaired glucose tolerance (IGT; 26.7 vs $0 \%, p=0.031$ ). While basal endogenous glucose production (EGP) was not different, white women had higher EGP and less EGP suppression than black women during the low-dose clamp. Only one white woman had incomplete suppression of EGP during the highdose clamp. $\mathrm{S}_{\mathrm{I}}$ and RER during the low-dose and high-dose clamps were similar between white and black women.

Correlates of insulin sensitivity In black women, body fat measures correlated negatively with hepatic and peripheral $\mathrm{S}_{\mathrm{I}}$, whereas in white women, only VAT correlated with $M / \mathrm{I}-$ high (Table 2). In black women only, liver fat correlated negatively with suppression of EGP, soleus fat correlated negatively with glucose infusion adjusting for circulating insulin concentrations (M/I)-low, and skeletal muscle IRS1, vesicle associated membrane protein (VAMP) and stearoyl-CoA desaturase 1 (SCD1) expression correlated positively with rate of disposal (Rd)-low and $M$ /I-high. In both black and white women, serum adiponectin correlated positively with peripheral $\mathrm{S}_{\mathrm{I}}$.

\section{Discussion}

The major findings of our study were that obese white women had reduced hepatic $\mathrm{S}_{\mathrm{I}}$ compared with obese black women, whereas peripheral $\mathrm{S}_{\mathrm{I}}$ did not differ. Significant associations between ectopic fat accumulation and $\mathrm{S}_{\mathrm{I}}$ were observed in obese black, but not white women, suggesting that obese black women are more sensitive to the effects of ectopic lipid deposition than obese white women.
Until recently, studies demonstrating ethnic differences in $\mathrm{S}_{\mathrm{I}}$ between black and white women $[1,2]$ have only measured whole-body $\mathrm{S}_{\mathrm{I}}$. DeLany et al [6] recently showed similar levels of hepatic $S_{I}$, but lower peripheral $S_{I}$ in young (22-24 years) normal-weight black vs white women. In contrast, in older obese women, we found that peripheral $\mathrm{S}_{\mathrm{I}}$ did not differ, but white women had lower hepatic $S_{I}$ than black women. Studies in the USA have consistently reported higher liver fat of white compared with black women [7], which is supported in part by our study. However, liver fat was associated with reduced hepatic and whole-body $\mathrm{S}_{\mathrm{I}}$ in black, but not white women. This indication of increased sensitivity to ectopic lipid deposition confirms data in African-Americans showing that for a given level of liver fat, black women were more insulin resistant than white women [7].

Although there were no ethnic differences in IMCL or EMCL content, IMCL was associated with lower $\mathrm{S}_{\mathrm{I}}$ during the low-dose clamp in black, but not white women. Studies from the USA that have shown similar [4] or lower [8] IMCL levels in black than white women, but have demonstrated associations with $\mathrm{S}_{\mathrm{I}}$ in white women only $[4,8]$. Differences between our study and others may relate to differences in methods used to measure $\mathrm{S}_{\mathrm{I}}$, or to differences in the accumulation of lipid byproducts. Supporting the latter, we showed that in black women only, $\mathrm{S}_{\mathrm{I}}$ was associated with skeletal muscle SCD1 expression. SCD1 converts saturated fatty acids to monounsaturated fatty acids and increases triacylglycerol esterification, thereby attenuating the accumulation of lipid metabolites such as diacylglycerol and ceramide, which interfere with insulin signalling [9]. Despite no ethnic differences in the skeletal muscle expression of insulin signalling genes, we showed that IRS1 and VAMP expression were associated with increased $S_{I}$ in black, but not white women. IRS1 is integral to insulin signalling, while VAMP is involved in insulin-stimulated GLUT4 translocation, and is upregulated in hyperinsulinaemia [10].

We used the state-of-the-art measures of $\mathrm{S}_{\mathrm{I}}$ and ectopic fat deposition, which have not been performed previously in an obese black African population. NEFAs were not measured during the clamp, precluding measurement of adipose tissue $\mathrm{S}_{\mathrm{I}}$; however, fasting and OGTT NEFA concentrations were not different between ethnicities (ESM Fig. 1). While the white women had a greater family history of type 2 diabetes and a higher prevalence of IFG and IGT, adjusting for these differences, or analysis of only women with normal glucose tolerance did not alter the main findings of this study. The paradox of higher hepatic $\mathrm{S}_{\mathrm{I}}$ but similar EGP in black compared with white SA women may be explained by lower hepatic insulin clearance in obese, insulin resistant black women [11]. Future studies that also include measures of C-peptide are required. Other limitations include self-reported alcohol intake and failure to control for the phase of the menstrual 
Table 1 Participant characteristics

\begin{tabular}{|c|c|c|c|c|}
\hline Variable & Obese white $(n=15)$ & Obese black $(n=15)$ & $p$ value & $p$ adjust FMI \\
\hline Age (years) & $36 \pm 4$ & $36 \pm 5$ & 0.978 & \\
\hline \multicolumn{5}{|l|}{ Body composition } \\
\hline BMI $\left(\mathrm{kg} / \mathrm{m}^{2}\right)$ & $35.2 \pm 3.5$ & $37.9 \pm 5.1$ & 0.106 & \\
\hline FFM (kg) & $52.4 \pm 7.4$ & $49.7 \pm 6.7$ & 0.297 & \\
\hline Fat mass (kg) & $42.5 \pm 6.1$ & $47.1 \pm 9.8$ & 0.131 & \\
\hline Body fat (\%) & $44.8 \pm 3.6$ & $48.4 \pm 3.4$ & 0.008 & \\
\hline FMI $\left(\mathrm{kg} / \mathrm{m}^{2}\right)$ & $15.4 \pm 2.2$ & $18.1 \pm 3.6$ & 0.017 & \\
\hline Waist (cm) & $97.6 \pm 7.5$ & $101.8 \pm 10.3$ & 0.207 & \\
\hline $\operatorname{VAT}\left(\mathrm{cm}^{2}\right)$ & $170 \pm 40$ & $179 \pm 45$ & 0.590 & 0.646 \\
\hline SAT $\left(\mathrm{cm}^{2}\right)$ & $534 \pm 89$ & $596 \pm 101$ & 0.085 & 0.903 \\
\hline \multicolumn{5}{|l|}{ Circulating proteins } \\
\hline Adiponectin (mg/l) & $4.4(3.2-5.9)$ & $2.7(2.0-3.8)$ & 0.025 & 0.022 \\
\hline hs-CRP (ng/ml) & $4.4 \pm 2.2$ & $5.2 \pm 2.8$ & 0.425 & 0.983 \\
\hline \multicolumn{5}{|l|}{ Ectopic fat } \\
\hline Liver fat (\%) & $3.6(1.2-9.5)$ & $1.5(1.1-2.1)$ & 0.077 & 0.065 \\
\hline TA IMCL & $148(90-274)$ & $119(42-143)$ & 0.070 & 0.206 \\
\hline Sol IMCL & $711(507-1080)$ & $925(506-1600)$ & 0.485 & 0.792 \\
\hline TA fat content $(\%)$ & $6.7(5.5-9.1)$ & $9.4(7.1-14.2)$ & 0.028 & 0.083 \\
\hline Sol fat content $(\%)$ & $10.8(9.7-14.7)$ & $15.5(13.4-18.9)$ & 0.003 & 0.074 \\
\hline \multicolumn{5}{|l|}{ Basal clamp } \\
\hline Fasting glucose (mmol/l) & $5.1 \pm 0.2$ & $5.1 \pm 0.4$ & 0.591 & 0.903 \\
\hline Fasting insulin $(\mathrm{pmol} / \mathrm{l})$ & $64.4 \pm 5.4$ & $90.7 \pm 39.1$ & 0.028 & 0.188 \\
\hline $\operatorname{EGP}\left(\mathrm{mg} \mathrm{min} \operatorname{mon}^{-1}[\mathrm{~kg} \mathrm{FFM}]^{-1}\right)$ & $2.6(2.0-3.8)$ & $2.7(1.8-2.9)$ & 0.335 & 0.497 \\
\hline Fasting RER & $0.73 \pm 0.04$ & $0.77 \pm 0.07$ & 0.076 & 0.084 \\
\hline Fasting RMR (kJ $[\mathrm{kg} \mathrm{FFM}]^{-1}$ day $^{-1}$ ) & $134(128-145)$ & $132(126-152)$ & 0.702 & 0.767 \\
\hline \multicolumn{5}{|l|}{ Low-dose clamp } \\
\hline Glucose-low (mmol/l) & $4.6 \pm 0.3$ & $4.6 \pm 0.3$ & 0.671 & 0.716 \\
\hline Insulin-low (pmol/l) & $134.1 \pm 42.6$ & $158.4 \pm 35.2$ & 0.100 & 0.237 \\
\hline EGP-low (mg min $\left.{ }^{-1}[\mathrm{~kg} \mathrm{FFM}]^{-1}\right)$ & $1.9(1.6-2.7)$ & $0.8(0-1.8)$ & 0.006 & 0.002 \\
\hline Suppression of EGP $(\%)$ & $17(5-51)$ & $56(29-100)$ & 0.006 & 0.002 \\
\hline$M$-low $\left(\mathrm{mg} \min ^{-1}[\mathrm{~kg} \mathrm{FFM}]^{-1}\right)$ & $0.75(0.39-1.98)$ & $1.19(0.33-3.73)$ & 0.757 & 0.187 \\
\hline$M / \mathrm{I}-\mathrm{low}\left(\mathrm{mg} \min ^{-1}[\mathrm{~kg} \mathrm{FFM}]^{-1} \mathrm{mmol} / \mathrm{l}^{-1}\right)$ & $0.31(0.15-0.80)$ & $0.39(0.09-0.91)$ & 0.871 & 0.320 \\
\hline Rd-low (mg min $\left.{ }^{-1}[\mathrm{~kg} \mathrm{FFM}]^{-1}\right)$ & $3.0(2.4-4.1)$ & $2.5(2.0-3.7)$ & 0.178 & 0.418 \\
\hline RER-low & $0.75 \pm 0.06$ & $0.77 \pm 0.06$ & 0.317 & 0.218 \\
\hline RMR-low (kJ [kg FFM] ${ }^{-1}$ day $^{-1}$ ) & $136(129-142)$ & $137(129-145)$ & 0.791 & 0.712 \\
\hline \multicolumn{5}{|l|}{ High-dose clamp } \\
\hline Glucose-high (mmol/l) & $4.4 \pm 0.4$ & $4.6 \pm 0.3$ & 0.300 & 0.376 \\
\hline Insulin-high (pmol/l) & $513.0 \pm 88.5$ & $589.0 \pm 133.4$ & 0.077 & 0.149 \\
\hline$M$-high $\left(\mathrm{mg} \mathrm{min}^{-1}[\mathrm{~kg} \mathrm{FFM}]^{-1}\right)$ & $9.3(5.7-12.2)$ & $8.5(4.8-12.2)$ & 0.962 & 0.631 \\
\hline$M / \mathrm{I}$-high $\left(\mathrm{mg} \min ^{-1}[\mathrm{~kg} \mathrm{FFM}]^{-1} \mathrm{mmol} / \mathrm{I}^{-1}\right)$ & $0.82(0.70-1.36)$ & $0.76(0.58-0.93)$ & 0.462 & 0.898 \\
\hline RER-high & $0.83 \pm 0.06$ & $0.85 \pm 0.08$ & 0.573 & 0.457 \\
\hline RMR-high (kJ $\left[\mathrm{kg} \mathrm{FFM}^{-1}\right.$ day $^{-1}$ ) & $139(133-153)$ & $137(130-156)$ & 0.964 & 0.731 \\
\hline
\end{tabular}

For non-normally distributed data, values are median (IQR), with $p$ values for $\log _{10}$-transformed data. For normally distributed data, values are means $\pm \mathrm{SD}$

EGP, calculated as the rate of appearance of glucose minus the glucose infusion rate; High-dose clamp, high-dose $\left(40 \mathrm{mU} \mathrm{m}^{-2} \mathrm{~min}^{-1}\right)$ insulin infusion; Low-dose clamp, low-dose $\left(10 \mathrm{mU} / \mathrm{m}^{-2} \mathrm{~min}^{-1}\right)$ insulin infusion; $M$, glucose infusion rate, which reflects whole-body insulin sensitivity; RMR, resting metabolic rate; Sol, soleus; Suppression of EGP, calculated as the \% change in EGP between baseline and the low-dose insulin infusion 
Table 2 Correlates of hepatic and peripheral insulin sensitivity

\begin{tabular}{|c|c|c|c|c|c|c|c|c|}
\hline \multirow[t]{2}{*}{ Variable } & \multicolumn{2}{|c|}{$\%$ Suppression of EGP } & \multicolumn{2}{|l|}{ Rd-low } & \multicolumn{2}{|l|}{$M /$ I-low } & \multicolumn{2}{|c|}{$M /$ I-high } \\
\hline & White & Black & White & Black & White & Black & White & Black \\
\hline \multicolumn{9}{|l|}{ Body composition } \\
\hline Body fat (kg) & 0.08 & $-0.64 *$ & -0.09 & -0.34 & 0.01 & $-0.64 *$ & 0.12 & $-0.60^{*}$ \\
\hline Waist & 0.09 & $-0.65^{* *}$ & -0.18 & $-0.73 * *$ & -0.25 & $-0.67 * *$ & -0.44 & $-0.73^{*}$ \\
\hline VAT & -0.04 & $-0.52 *$ & -0.20 & -0.35 & -0.34 & $-0.62 *$ & $-0.62 *$ & -0.30 \\
\hline SAT & 0.19 & $-0.54 *$ & -0.21 & -0.26 & 0.13 & -0.45 & 0.17 & $-0.50^{*}$ \\
\hline \multicolumn{9}{|l|}{ Ectopic fat } \\
\hline Liver fat & 0.28 & $-0.57^{*}$ & -0.44 & -0.41 & -0.45 & -0.34 & -0.53 & -0.21 \\
\hline Soleus IMCL & $0.59 *$ & -0.46 & -0.16 & -0.52 & 0.12 & $-0.62 *$ & -0.08 & -0.46 \\
\hline Soleus fat $(\%)$ & 0.34 & $-0.56^{*}$ & -0.04 & -0.40 & 0.27 & $-0.66^{*}$ & 0.09 & -0.33 \\
\hline \multicolumn{9}{|c|}{ Muscle gene expression } \\
\hline IRS & -0.32 & 0.49 & 0.04 & $0.65 *$ & -0.15 & $0.56^{*}$ & -0.37 & $0.66^{*}$ \\
\hline VAMP & -0.37 & 0.43 & -0.07 & $0.68 * *$ & -0.18 & 0.52 & -0.49 & $0.64 *$ \\
\hline SCD1 & -0.33 & 0.49 & -0.03 & $0.90 * *$ & -0.23 & 0.53 & -0.29 & $0.72 * *$ \\
\hline \multicolumn{9}{|l|}{ Circulating adipokines } \\
\hline Adiponectin & 0.41 & 0.49 & 0.47 & $0.77 * *$ & $0.64 * *$ & $0.56^{*}$ & $0.75^{* *}$ & $0.71 * *$ \\
\hline
\end{tabular}

Values are Pearson correlation coefficients

${ }^{*} p<0.05,{ }^{*} p<0.01$

$M /$ I-high, $M / \mathrm{I}$ corrected for circulating insulin levels during the high-dose (40 $\mathrm{mU} \mathrm{m}^{-2} \mathrm{~min}^{-1}$ ) clamp; $M / \mathrm{I}-$ low, $M / \mathrm{I}$ corrected for circulating insulin levels during the low-dose clamp; Rd-low, Rd during the low-dose $\left(10 \mathrm{mU} \mathrm{m}^{-2} \mathrm{~min}^{-1}\right)$ clamp

cycle, which may have confounded our results. Further, we only included obese women; therefore these results cannot be extrapolated to non-obese women, or to men.

In conclusion, we found that although whole-body $\mathrm{S}_{\mathrm{I}}$ was not different between obese black and white women, obese white women presented with lower hepatic $\mathrm{S}_{\mathrm{I}}$ compared with obese black women. Notably, ectopic fat accumulation was associated with reduced $S_{I}$ in black, but not white women. Future studies are required to gain an understanding of why black women are more sensitive to the effects of ectopic fat deposition than white women.

Acknowledgements The authors wish to thank the research volunteers for their participation in this study. J. Bergman of Symington Radiology and E. Meintjes of the MRC/UCT Medical Imaging Research Unit, Department of Human Biology, University of Cape Town, Cape Town, South Africa are thanked for their assistance with the MRS scans. L. Bewerunge is thanked for performing the DXA scans. We would like to thank I. Söderström of Umeå University, Umeå, Sweden for performing the serum analyses, L. Mokwena of Stellenbosch University, Stellenbosch, South Africa for performing the GCMS analyses, and K. Yarasheski of Washington University School of Medicine, St Louis, MO, USA for assistance with GCMS analysis and interpretation.

Funding This study was funded by the National Research Foundation of South Africa (Grant no. 73707), the United States Department of Veterans Affairs, the Swedish Research Council (K2011-12237-15-6), the Swedish Heart and Lung Foundation and Umeå University, Sweden.
Duality of interest The authors declare that there is no duality of interest associated with this manuscript.

Contribution statement JHG, CW, KU, SEK and TO contributed to the conception and design of the work; JHG, DK, CW, JF, JH, HV, KU, EVL and TO contributed to the acquisition and analysis of the data; JHG, $\mathrm{DK}, \mathrm{JH}, \mathrm{KU}, \mathrm{NSL}, \mathrm{SEK}$ and TO contributed to the interpretation of the data; JG, DK, and TO contributed to drafting the article; all authors revised the manuscript critically for important intellectual content and approved the final version to be published. JHG is the guarantor of this work.

\section{References}

1. Goedecke JH, Dave JA, Faulenbach MV et al (2009) Insulin response in relation to insulin sensitivity: an appropriate beta-cell response in black South African women. Diabetes Care 32:860 865

2. Haffner SM, D'Agostino R, Saad MF et al (1996) Increased insulin resistance and insulin secretion in nondiabetic African-Americans and Hispanics compared with non-Hispanic whites. The Insulin Resistance Atherosclerosis Study. Diabetes 45:742-748

3. Liska D, Dufour S, Zern TL et al (2007) Interethnic differences in muscle, liver and abdominal fat partitioning in obese adolescents. PLoS ONE 27:e569

4. Ingram KH, Lara-Castro C, Gower BA et al (2009) Intramyocellular lipid and insulin resistance: differential relationships in European and African Americans. Obesity Nature Publishing Group 19: 1469-1475 
5. Goedecke JH, Levitt NS, Lambert EV et al (2009) Differential effects of abdominal adipose tissue distribution on insulin sensitivity in black and white South African women. Obesity (Silver Spring) 17:1506-1512

6. DeLany JP, Dubé JJ, Standley RA et al (2014) Racial differences in peripheral insulin sensitivity and mitochondrial capacity in the absence of obesity. J Clin Endocrinol Metab 99:4307-4314

7. Guerrero R, Vega GL, Grundy SM, Browning JD (2009) Ethnic differences in hepatic steatosis: an insulin resistance paradox? Hepatology 49:791-801

8. Smith LM, Yao-Borengasser A, Starks T, Tripputi M, Kern PA, Rasouli N (2010) Insulin resistance in African-American and Caucasian women: differences in lipotoxicity, adipokines, and gene expression in adipose tissue and muscle. J Clin Endocrinol Metab 95:4441-4448
9. Pinnamaneni SK, Southgate RJ, Febbraio MA, Watt MJ (2006) Stearoyl CoA desaturase 1 is elevated in obesity but protects against fatty acid-induced skeletal muscle insulin resistance in vitro. Diabetologia 49:3027-3037

10. Maier VH, Melvin DR, Lister CA, Chapman H, Gould GW, Murphy GJ (2000) v-and t-SNARE protein expression in models of insulin resistance: normalization of glycemia by rosiglitazone treatment corrects overexpression of cellubrevin, vesicleassociated membrane protein-2, and syntaxin 4 in skeletal muscle of Zucker diabetic fatty rats. Diabetes. Am Diabetes Assoc 49:618 625

11. Rasouli N, Spencer HJ, Rashidi AA, Elbein SC (2007) Impact of family history of diabetes and ethnicity on $\beta$-cell function in obese, glucose-tolerant individuals. J Clin Endocrinol Metab 92:46564663 